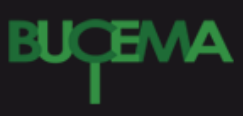

Bulletin du centre d'études médiévales d'Auxerre | BUCEMA

Hors-série $n^{\circ} 7 \mid 2013$

Les nouveaux horizons de l'ecclésiologie : du discours clérical à la science du social

\title{
Auctoritas y potestas en la exégesis bíblica carolingia
}

\section{Alfonso Hernández Rodríguez}

\section{(2) OpenEdition \\ 12 Journals \\ Edición electrónica \\ URL: https://journals.openedition.org/cem/12774 \\ DOI: $10.4000 /$ cem. 12774 \\ ISSN: 1954-3093 \\ Editor \\ Centre d'études médiévales Saint-Germain d'Auxerre}

Referencia electrónica

Alfonso Hernández Rodríguez, « Auctoritas y potestas en la exégesis bíblica carolingia », Bulletin du centre d'études médiévales d'Auxerre | BUCEMA [En ligne], Hors-série $n^{\circ} 7$ | 2013, mis en ligne le 11 juin 2013, consulté le 04 mars 2023. URL : http://journals.openedition.org/cem/12774 ; DOI : https:// doi.org/10.4000/cem. 12774

Este documento fue generado automáticamente el 4 marzo 2023.

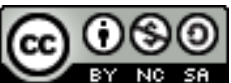

Creative Commons - Attribution - Pas d'Utilisation Commerciale - Partage dans les Mêmes Conditions 4.0 International - CC BY-NC-SA 4.0

https://creativecommons.org/licenses/by-nc-sa/4.0/ 


\title{
Auctoritas y potestas en la exégesis bíblica carolingia
}

\author{
Alfonso Hernández Rodríguez
}

El presente trabajo tiene su origen en la preocupación acerca de la naturaleza de las representaciones sobre el poder en la Alta Edad Media, en particular aquellas eclesiásticas. El gelasianismo ha sido uno de los conceptos tradicionalmente utilizados para explicar las construcciones intelectuales que le permitieron a la Iglesia sostener ideológicamente su espacio de poder en la sociedad altomedieval.

Quienes lo utilizan consideran que la institución eclesiástica basó su derecho al ejercicio del poder en la tierra sobre una división dual del mismo. Habría una esfera de poder espiritual, una auctoritas, depositada en la Iglesia y ante todo en los obispos y el papa, superior a otra esfera terrenal, la potestas, propia de los príncipes de la tierra (emperadores, reyes, etc.). El creador de esta idea de división dual habría sido el papa Gelasio, quien la expresara con claridad en 494 en una famosa carta dirigida al Emperador Anastasio.

3 Sin embargo, una corriente historiográfica se ha opuesto a esta visión tradicional. En particular mencionaremos a dos autores: Gilbert Dagron y Pierre Toubert. Gilbert Dagron en su ya clásico Empereur et prêtre afirmaba que era poco probable que Gelasio haya intentado atacar el derecho a la auctoritas del emperador, que implicaba el derecho a legislar para dejarle solo la potestas que lo convertía solo en un funcionario. Convertir la afirmación de Gelasio en la base de una teocracia es ir demasiado lejos y, sostenía Dagron, que "l'historiographie occidentale vit une révolution des idées là où il n'y avait peut-être qu'une très habile rhétorique ${ }^{1}{ }^{1}$.

Dentro de una lógica similar, Pierre Toubert publicó un artículo dedicado al uso del concepto de Gelasianismo en el periodo carolingio. Para este autor, ni el texto de Gelasio cumplió una función importante en las luchas de poder entre laicos y eclesiásticos, en ese momento de la historia europea, ni se construyó a partir de el una teoría gelasiana de los dos poderes, ni siquiera fue un texto muy utilizado y las pocas veces que sí lo fue en general se trató de citas o corrompidas o distorsionadas ${ }^{2}$. Para 
Toubert, en última instancia, el Duo quippe fue un texto más en la construcción del poder episcopal carolingio y no el eje de una eclesiología gelasiana.

Sin embargo, en un artículo publicado en 2005, Yves Sassier responde directamente al artículo de Toubert ${ }^{3}$. Esto no es para nada extraño, puesto que el 'gelasianismo' es un instrumento central de análisis para Sassier ${ }^{4}$. El artículo de Sassier es muy erudito, aunque no parece ser concluyente. El autor hace un rastreo textual desde la antigüedad romana con el objetivo de sostener la noción de 'gelasianismo', o sea, que Gelasio distinguió con claridad una auctoritas episcopal o papal de una potestas imperial, una esfera de la autoridad religiosa de una esfera del poder laico, puesto en términos modernos. Por lo tanto, se opone a la posición de Dagron y Toubert. El problema con el artículo de Sassier para el periodo carolingio es que, aunque encuentra algunos textos 'nuevos' en los que los términos auctoritas y potestas, parecen ser utilizados en el sentido que se le atribuye Gelasio, lo que de por sí sigue siendo un problema, se sigue moviendo dentro de un corpus de textos y de autores bastante tradicional. Aporta interpretaciones a favor del 'gelasianismo', pero no pruebas concluyentes de que la inspiración detrás de los autores que utilizan las nociones de auctoritas y potestas haya sido el Duo quippe. Su rastreo es tan minucioso y sus descubrimientos tan puntuales y a veces discutibles, que parece terminar demostrando lo contrario de lo que se propuso originalmente.

Entiendo que para resolver el problema del significado de la pertinencia del concepto de gelasianismo en la Alta Edad Media, antes de la Reforma Gregoriana, es necesario recurrir a una nueva aproximación al tema de la división de esferas del poder. Esto solo es posible asumiendo algunas ideas básicas: en primer lugar que se debe recurrir a nuevas fuentes, lo que significa ampliar la investigación a textos que no han sido estudiados, o sea salir del canon de textos tradicional para el estudio del pensamiento político altomedieval. En segundo lugar, es necesario tener en cuenta que las ideas acerca del poder y de la organización de la sociedad en la Alta Edad Media no se presentan como tratados sistemáticos, sino que están implícitas en textos muy diferentes. La matriz de pensamiento es muy diferente no solo a la de la modernidad, sino también a la de la escolástica. El eje central de la misma son las Sagradas Escrituras y las reflexiones son ante todo eclesiológicas. No se piensa en la sociedad, el estado o el reino, sino que es la Iglesia el marco dentro del que están incluidas todas esas realidades.

7 En este trabajo me propongo presentar el problema de auctoritas y potestas en el periodo carolingio partiendo de un corpus no convencional. Haré uso de fuentes exegéticas de mediados del siglo Ix. La presentación estará limitada a un autor: Haimón de Auxerre, quien ha sido el centro de mi trabajo de doctorado. Haimón fue el segundo de los cuatro maestros de la llamada escuela de Auxerre ${ }^{5}$. Su obra es principalmente exegética (la escribió entre 840 y 865) y la tradición manuscrita conservada es muy importante. Los datos biográficos acerca de Haimón son casi inexistentes, lo que sabemos de él es aquello que se puede inferir a través de sus escritos ${ }^{6}$.

8 He utilizado la versión digitalizada de la Patrologia Latina para buscar en los textos exegéticos del mencionado autor los dos términos (auctoritas y potestas) con el objetivo de ver en qué contexto las utiliza, cuál es su significado y si puede atribuirse su uso a una influencia gelasiana. 


\section{Auctoritas}

Como es esperable en un exegeta bíblico del siglo IX, para Haimón la autoridad en última instancia reside en dios. Dice en su comentario a Joel IV, 2:

Hoc est, non eos opprimam in die judicii, aut auctoritatem potentiae meae sentiant, sed ratione justitiae, aut etiam sua confessione... ${ }^{7}$

Esta cita tiene la particularidad además de combinar auctoritas con potentia, un término cercano a potestas.

11 La auctoritas pertenece también a Cristo, no solo a Dios Padre, como en el comentario a Cor. III:

....architectus est, qui ejus a quo instructus est, voluntatem et auctoritatem imitatur, sicut fecit Paulus Christi doctrinam imitando, non alia praedicans...

\section{Comentario a Malaquías:}

Interpretatur angelus Domini, sive angelus meus, quia tantae fuit auctoritatis, ut quidquid dixisset, ita crederetur velut ab angelo Domini dictum...

Solo he podido encontrar el término auctoritas asociado a una autoridad religiosa en una ocasión en un texto de Haimón. Se trata del comentario a Os VI, 8:

In hac urbe (Galaad) primitus idolum est consecratum, quia habitabatur a sacerdotibus.Erat enim et civitas fugitivorum, sed quanto celebrior et maioris erat auctoritatis, quia in partem sacerdotum fuerat delegata, tanto principium idololatrie et malorum omnium fuit et, quia isti primum idola consecrarunt, primi ab Assiriis capti [...] ita sacerdotes Galaad insidiantes simplicitati populi, expoliabant eos fide et interficiebant mente.

14 Estos sacerdotes de la ciudad de Galaad eran idólatras. Es el único lugar en los textos de Haimón en el que el término auctoritas es utilizado en un contexto negativo. En ninguno de los textos que he utilizado para este trabajo Haimón relaciona auctoritas con la autoridad episcopal.

Queda pendiente entonces el problema: si la fuente de la auctoritas es Dios, pero Haimón no declara que los depositarios de esta sean ni sacerdotes ni obispos, ¿dónde reside la autoridad en la Tierra?

Una primera respuesta la podemos encontrar en su Comentario al Cantar de los Cantares II, 13:

...in Christum crederent, et tamen legem carnaliter observare vellent, magisque auctoritate legis delectarentur quam dulcedine Evangelii, volentes circumcisionem, sabbatum et... ${ }^{8}$

La autoridad está en la Ley. En este caso la ley es la Ley del Antiguo Testamento, que en el rigorismo de los judíos se opone a la dulzura del Evangelio.

Sin embargo, este último más adelante en el mismo comentario a Cant. VI, 11 es también fuente de autoridad:

...non currus, sed quadrigas appellat, quia Evangelii praedicatio quatuor evangelistarum auctoritate consistit, et quatuor Evangelia quasi quadrigae sunt Novi Testamenti, cui... ${ }^{9}$

Por lo tanto, hay una autoridad depositada tanto en la Ley del Antiguo Testamento, como en el Evangelio, aunque la primera sea más dura que la segunda.

La idea de que la autoridad de origen divino se deposita en las escrituras es central en el pensamiento de Haimón. Además de los ejemplos ya citados, la podemos encontrar en los comentarios a Romanos: 
...omnis illa Scriptura testimonium perhibebat: et quoniam ad mortem contra auctoritatem illius Scripturae tradiderunt Christum, illata est eis retributio, secundum meritum... ${ }^{10}$

En el Comentario al Apocalipsis:

...vel caetera talia, quae etiam nunc evangelica auctoritate servari jubentur. ${ }^{11}$

También he encontrado numerosas afirmaciones similares en el Homiliario de Haimón ${ }^{12}$.

Hay otro nivel de autoridad que pertenece a la de los Doctores (apóstoles y padres de la Iglesia), como se puede leer en el comentario a I Corintios:

...nomine Pauli, in Epistola ad Romanos, prout melius cognoscere potuimus, auctoritate doctorum dicere studuimus, et quomodo ipse vocatus sit apostolus... ${ }^{13}$

17 y más abajo también en I Corintios:

Cujus auctorem criminis non aliter permittitur nobis damnare, secundum auctoritatem sanctorum Patrum, nisi aut confessus, aut convictus fuerit testibus. ${ }^{14}$

La autoridad puede recaer también en la palabra profética, como señala nuestro autor en el comentario a Apoc. I, 3:

Hinc autem liquido colligitur, quantae sit auctoritatis, quantaeque excellentiae, cum inter omnes libros Novi Testamenti hic solummodo prophetia nominatur, quam qui observarerit beatus esse perhibetur. ${ }^{15}$

En los textos exegéticos de Haimón hay distintos niveles de autoridad. La más alta es indudablemente la divina. La autoridad divina puede estar en la boca de un ángel. Pero ante todo, en la Tierra la autoridad divina se ha depositado en los textos: Doctores, Padres, incluso profetas han dejado textos. Estos son las Sagradas Escrituras (Antiguo y Nuevo Testamento) y escritos patrísticos. La autoridad emana de Dios para depositarse en los escritos que la conservan. Para Haimón la autoridad es ante todo propiedad de la palabra escrita. Por otra parte sabemos que nuestro autor es un exegeta de las Sagradas Escrituras que utiliza como principal instrumento los escritos de los Padres. Ha sido señalado también en numerosas ocasiones en la crítica historiográfica moderna que él propone una eclesiología en cuya cúspide se encuentra una pequeña elite de monjes intérpretes de las Sagradas Escrituras. Por lo tanto, para Haimón los depositarios de la autoridad en la Tierra no ni sacerdotes, ni obispos, sino ese pequeño grupo de hombres dedicados a la exegesis y a la vida contemplativa, que aislados de las tentaciones del mundo material pueden escuchar la vos del Señor y que ocupan en la Iglesia el lugar de los profetas del Antiguo Testamento.

\section{Potestas}

Haimón asocia a Dios con la palabra potestas solamente una vez en sus textos exegéticos, se trata del comentario a Isaías:

« Manus enim Domini tetigit me.» Unde diabolus sciens potestatem in manu Domini esse, et in brachio ejus... ${ }^{16}$

El autor señala que la potestas está in manu Domini. Esto quiere decir que la potestas del Diablo no existe sino como concesión de Dios. La fuente de Haimón es sin duda el In Isaiam de Jerónimo:

...enim Domini tetigit me (Job. XIX, 21). Unde et diabolus sciens potentem manum

Domini, et brachium quod universis gentibus revelatum... ${ }^{17}$

Está claramente establecido en los estudios sobre el autor y sobre la Escuela de Auxerre que sus maestros se sirven muy libremente de las fuentes patrísticas. El cambio que 
Haimón realiza sobre el texto de Jerónimo es muy interesante. En lugar de potentem él utiliza potestatem. Cambia un adjetivo por un sustantivo y realiza la exégesis de su propio cambio : la potestas pertenece a Dios y el Diablo lo reconoce.

Sin embargo, la relación entre potestas y el Diablo es mucho más habitual, como en el comentario a Isaias:

«Jugum et virgam,» diaboli, id est, dominationem et potestatem. «Et sceptrum,» id est, imperium, quod per universum orbem tenebat:... ${ }^{18}$

Este fragmento presenta al Diablo como depositario no solo de la potestas, sino también de la dominatio e incluso del imperium. Todos estos términos pueden ser utilizados para describir el poder de los laicos sobre la Tierra, pero a todos ellos Haimón les otorga una carga negativa cuando los asocia al Demonio. De hecho la potestas es atributo habitual del Diablo o de los demonios:

...et innocentiam columbae imitantes, ut postmodum possint avolare de potestate

daemonum, ut collocentur in domibus suis, hoc est in coelestibus... ${ }^{19}$ y poderes de este mundo, como los romanos, sin embargo también puede ser asociada a fuerzas espirituales positivas (Pedro) o negativas como el Diablo y los Demonios. La potestas es un atributo mucho más amplio que la auctoritas y, aunque Haimón conceda su origen en la divinidad, sin embargo, pareciera tratarse antes que nada de un mal necesario. Quizás esta imagen del poder se origine en la influencia del pensamiento de san Agustín sobre nuestro autor. En todo caso habría que establecer relaciones textuales más concretas. A pesar de la carga negativa del concepto potestas, sin embargo Haimón no hace un uso diferenciado de éste: no hay una potestas terrenal, depositada en las autoridades laicas de este mundo, separada y diferente de una auctoritas espiritual propia de la jerarquía eclesiástica. Existen tanto potestates terrenales como espirituales.

...quo gaudebat per suam passionem redimi mundum de diabolica potestate. ${ }^{20}$

La potestas no es solo un atributo demoniaco, sino también humano. De los romanos en a Isaías:

Principem suum Romanae tradidit potestati, et ipse Romanae subjectus est servituti. ${ }^{21}$

De los príncipes y reyes en Cantar de los cantares:

Per hos autem montes, saeculi potestates, reges videlicet et principes, intelliguntur, qui veluti montes in superbia... ${ }^{22}$

...viro est mulier, vivente viro, alligata est legi, id est potestati viri: si autem mortuus fuerit vir ejus, soluta est a... ${ }^{23}$

Pero también puede recaer en Pedro como en Apocalipsis:

...esse in coelo, quemadmodum sunt in ostio, sed per claves potestas intelligitur ligandi atque solvendi. Ita ergo et hic clavium nomine... ${ }^{24}$

Como hemos podido ver no se puede decir que Haimón esté influenciado verdaderamente por alguna forma de gelasianismo en su utilización de los conceptos auctoritas y potestas y creo que podemos desechar el uso de este concepto, al menos para analizar el pensamiento de este autor.

Bulletin du centre d'études médiévales d'Auxerre | BUCEMA, Hors-série $n^{\circ} 7 \mid 2013$ 

problema desde un nuevo punto de vista. En lugar de rastrear arqueológicamente los orígenes gelasianos de la separación de las dos esferas de poder y autoridad, habría que pensar si estas no fueron construidas en un momento determinado de la historia del occidente cristiano, quizás entre los siglos IX y X, y, si así fuera, de qué manera esto aconteció. Si se toma este punto de vista, entonces el uso gregoriano de la carta de Gelasio puede ser vista como la hoz que levanta la cosecha después de dos siglos de que esta fuera sembrada. La separación de las dos esferas que reclama la Reforma gregoriana fue quizás en el siglo XI un fruto ya maduro que estaba esperando para caer $\mathrm{y}$ los intelectuales benedictinos de los siglos Ix y x quienes lo hicieron madurar.

Sin embargo, quiero extraer una conclusión más amplia de esta presentación: la pertinencia de la utilización de fuentes no-tradicionales (en este caso las exegéticas) para el estudio del pensamiento político o acerca del poder en la Alta Edad Media en general y en el periodo carolingio en particular. No solo por la importancia de estas fuentes en el momento que fueron redactadas, sino también por la tradición que muchos de esos textos tuvieron en los siglos posteriores de la Edad Media.

Los textos exegéticos no solo son un producto carolingio que circularon solo en ese periodo, sino que perduraron durante toda la Edad Media y el Renacimiento. En este sentido tuvieron mucha más tradición que, por ejemplo, los espejos de príncipes carolingios. Establezcamos una comparación: el famoso De institutione regia de Jonás de Orleáns ha sido uno de los textos más estudiados, para reconstruir la ideología política en tiempos carolingios. La importancia que se le ha otorgado es tal que fue editado críticamente dos veces en el siglo $\mathrm{xx}^{25}$. De más está decir que es un texto importante y de gran interés para la crítica histórica, sin embargo, la tradición manuscrita del mismo es muy escasa, solo se conservan tres manuscritos y, según su último editor, el escrito de Jonás permaneció en el olvido hasta el siglo XVII ${ }^{26}$. Si comparamos la tradición del De institutione con algunos comentarios exegéticos de Haimón como por ejemplo el Comentario a Oseas, podemos notar con facilidad que la tradición manuscrita del último es seis veces mayor y que abarca desde el 900 hasta la primera edición impresa en el siglo xvi. Por supuesto, sin llevar la comparación al Comentario al Cantar de los Cantares, cuarenta veces superior o al Comentario a las cartas paulinas de Haimón, cuya tradición manuscrita es cerca de sesenta veces la del De institutione. Los tres textos de Haimón ya han sido explotados por diferentes historiadores, filósofos y teólogos como fuentes para la historia del pensamiento político y eclesiológico carolingio. A la tradición manuscrita ininterrumpida durante toda la Edad Media hay que sumar el uso de estos textos en la construcción de la Glossa Ordinaria y las ediciones de los siglos XVI y XVII. Esto significa que los tres textos que mencioné de Haimón fueron copiados, citados e impresos $\mathrm{y}$, sobre todo, leídos continuamente durante ocho siglos. Lo que quiero señalar con estas comparaciones, es que es mucho más probable que un lector medieval -carolingio o posterior- haya construido su imagen del mundo, a partir de la lectura de los textos exegéticos de hombres de letras como Haimón antes que de los espejos de príncipes carolingios. 


\section{NOTAS}

1. G. DAGRON, Empereur et prêtre. Étude sur le 'césaropapisme' byzantin, 1996, p. 311.

2. P. TOUBERT, «La doctrine gélasienne des deux pouvoirs: une revisión », in L'Europe dans sa première croissance. De Charlemagne à l'An mil, Paris, 2004, p. 391-399.

3. Y. SASSIER, « Auctoritas pontificum et potestas regia : faut-il tenir pour négligeable l'influence de la doctrine gélasienne aux temps carolingiens?», in C. CAROZZI, H. TAVIANI-CAROZZI, (éds.), Le pouvoir au Moyen Âge. Idéologies, pratiques, représentations, 2005, p. 213-236.

4. Y. SASSIER, Royauté et idéologie au Moyen Âge. Bas-Empire, monde franc, France (IV e$\mathrm{XII}^{\mathrm{e}}$ siècle), Paris, 2002.

5. Para comprender el surgimiento de la escuela de Auxerre en el contexto del pensamiento carolingio ver J. MARENBON, From the Circle of Alcuin to the School of Auxerre, Logic, Theology and Philosophy in Early Middle Ages, Cambridge, 1981. Sin embargo el libro fundamental para iniciarse en el estudio de la escuela de Auxerre sigue siendo la recopilación de los Entretiens d'Auxerre, que tuvieron lugar en esa ciudad in 1989: D. IOGNA-PRAT, C. JEUDY, G. LOBRICHON (dir.), L'École Carolingienne d'Auxerre. De Murethach à Remi 830-908, Paris, 1991. En 2005 se realizó otro encuentro para tratar acerca de Haimón de Auxerre en particular, las actas fueron publicadas in 2007, S. SHIMAHARA (éd.), Études d'exégèse carolingienne: autour d'Haymon d'Auxerre. Atelier de recherches Centre d'Études médiévales d'Auxerre 25-26 avril 2005, Turnhout, 2007.

6. E. RIGGENBACH, Historische Studien zum Hebräerbrief. I: die Älsten lateinischen Kommentare zum Hebräerbrief. Forschungen zur Geschichte des neutestamentlichen Kanons 8, Leipzig, 1907. El trabajo más profundo para el problema de la atribución de los textos de Haimón sigue siendo D. IOGNA-PRAT, «L'oeuvre d'Haymon d'Auxerre ", in L'École Carolingienne d'Auxerre..., op. cit., p. 157-179.

7. HAIMÓN, In Joel, PL 117, col. 105.

8. HAIMÓN, In Cantica Canticorum, PL 117, col. 306C. La fuente de Haimón es CASIODORO, In Cantica Canticorum, PL 70, col. 1065D.

9. HAIMÓN, In Cantica Canticorum, PL 117, col. 6, col. 341B. Cf. CASIODORo, In Cantica Canticorum, PL 70, col. 1093A.

10. HAIMÓN, In Divi Pauli Epistolas, PL 117, col. 459D.

11. HAIMÓN, In Apocalypsin, PL 117, col. 1016B.

12. HAIMÓN, Homilia vii. Dominica quarta adventus: “...es Christus, neque Elias, neque propheta?» Ac si dicerent: Cujus auctoritatis es, ut novam doctrinam audeas docere, et inauditum prius hominibus..."; Homilia viii. In vigiliis nativitatis domini: “...haereticorum opinationem soli sunt, quos fratres sequuntur alii: sed juxta auctoritatem Scripturarum, omnes qui primi vulvam aperiunt, sive fratres eos aliqui,...”; Homilia x. De sancto stephano protomartyre: “...festivitatem celebramus, quia ad praedicandum ordinatus ab apostolis, cum ex auctoritate divinae legis

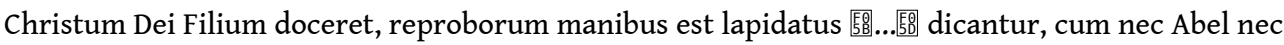
Zachariam ipsi occiderint, intelligat quia auctoritas sacrae Scripturae est, duas generationes commemorare, bonorum scilicet et malorum...."; Homilia xiii. Dominica infra octavam nativitatis domini: “...contradixerunt Donatistae haeretici; sed horum omnium contradictiones, divinae Scripturae conculcat auctoritas. His enim qui dixerunt virginem impossibile esse concipere et parere,..."

13. HAIMÓN, In Divi Pauli Epistolas, PL 117, col. 509A

14. HAIMÓN, In Divi Pauli Epistolas, PL 117, col. 531C.

15. HAIMÓN, In Apocalypsin, PL 117, col. 942B-C.

Bulletin du centre d'études médiévales d'Auxerre | BUCEMA, Hors-série $n^{\circ} 7$ | 2013 
16. HAIMÓN, In Isaiam, PL t. 116, col. 753A.

17. JERÓNIMO, In Isaiam, PL Liber II.

18. HAIMÓN, In Isaiam, PL 116, col. 770B.

19. HAIMÓN, In Osee, XI, 11.

20. HAIMÓN, In Cantica Canticorum, PL 117, col. 314C.

21. HAIMÓN, In Isaiam, PL t. 116, col. 139D. Cf. JERÓNIMO, In Isaiam, PL 24, col. 66A.

22. HAIMÓN, In Cantica Canticorum, PL 117, col. 319D. Cf. CASIODORO, In Cantica Canticorum, PL 70, col. 1076B.

23. HAIMÓN, In Divi Pauli Epistolas, PL 117, col. 419B.

24. HAIMÓN, In Apocalypsin, PL 117, col. 961A.

25. J. REVIRON, Les idées politico-religieuses d'un évêque du IX siècle. Jonas d'Orléans et son 'De institutione regia', Paris, 1930 ; JONAS D’ORLÉANS, Le Métier de Roi (De institutione regia). Introducción, texto crítico, traducción, notas e índice de A. DUBREUCQ, Sources Chrétiens 407, 1995.

26. JONAS D’ORLÉANS. Le Métier de Roi (De institutione regia)..., A. DUBREUCQ (éd.), p. 132-136.

ÍNDICE

Mots-clés: auctoritas, potestas, gélasianisme, éxegèse biblique carolingienne

\section{AUTOR}

ALFONSO HERNÁNDEZ RODRÍGUEZ

Université de Buenos Aires-CONICET 